\title{
Evolution of Autonomic Function Test in Type 2 Diabetes Mellitus Patients in Western Rajasthan: A Case Control Study
}

Shilpa Solanki*, Dr. Raghuveer Choudhary

Department of Physiology, Dr. S. N. Medical College, Jodhpur, India

DOI: $10.36347 /$ sasjm.2020.v06i05.003

| Received: 21.04.2020 | Accepted: 30.04.2020 | Published: 30.05 .2020

*Corresponding author: Shilpa Solanki

Abstract

Original Research Article

Neuropathy is one of the most common complication of diabetes. Therefore the present study was find out the evaluation of autonomic dysfunctions in Western Rajasthan type 2 diabetic patients will be helpful in their management. This case-control study was carried out on 240 subjects were divided into two groups i.e. control 120 and diabetic 120 (60 male: 60 female) (25-60 years). To assess the autonomic functions CANWin device was used. Our study concluded that values of parasympathetic tests were observed to be lower and sympathetic tests were higher in diabetic, when compare with control and statistically highly significant $(\mathrm{p}<0.001)$. In our study, patients with DM were found to have both sympathetic and parasympathetic dysfunctions due to hyperglycaemic effect.

Keywords: CAN, CANWin, DM, E/I ratio, VM ratio, 30:15 ratio, $\triangle \mathrm{SBP}$ and $\triangle \mathrm{DBP}$.

Copyright @ 2020: This is an open-access article distributed under the terms of the Creative Commons Attribution license which permits unrestricted use, distribution, and reproduction in any medium for non-commercial use (NonCommercial, or CC-BY-NC) provided the original author and source are credited.

\section{INTRODUCTION}

Type 2 diabetes mellitus is the most common type of diabetes in the world constituting $90 \%$ of the diabetic population. Neuropathy is one of the most common complication of diabetes. Cardiovascular Autonomic Neuropathy (CAN) is one of the most overlooked complications of diabetes mellitus and is clinically important because of its life threatening consequences $^{1}$. Cardiovascular Autonomic Neuropathy (CAN) results from the damage to the autonomic nerve fibres that innervates the heart and blood vessels and it causes, abnormalities in the control of heart rate and vascular dynamics [2].

Cardiovascular Autonomic Neuropathy (CAN) is a serious complication of diabetes, which is associated with cardiovascular morbidity causing mortality in people with Type 2 diabetes mellitus. In keeping with the recommendations of the American Diabetes Association 1992, five standard cardiovascular reflex tests are used to assess cardiovascular autonomic function. These includes changes in heart rate during deep timed breathing, Valsalva manoeuver and standing up to assess the cardiac parasympathetic activity and blood pressure responses to standing up and sustained handgrip to evaluate the sympathetic nervous activity [3]. Thus, the presence of Cardiovascular Autonomic Neuropathy is clinically important form of diabetic autonomic neuropathy, which is associated with an increased risk of silent myocardial ischemia, cardiac arrest and sudden death [4]. There have been only few studies in Western Rajasthan on autonomic nervous system changes in diabetic subjects. Therefore the present study was find out the evaluation of autonomic dysfunctions in Western Rajasthan type 2 diabetic patients will be helpful in their management.

\section{MATERIAL AND METHODS Study Design and Setting}

A case-control study was carried out in the Physiology department of Dr. S.N. Medical College, Jodhpur (Rajasthan). Sample size calculation: Sample size was calculated by using OpenEpi software with power $80 \%$, significance level alpha at 0.05 . The total sample size required was 114 subjects. Participants and sample size: This case-control study was carried out on 240 subjects in Western Rajasthan population. The subjects were divided into two groups i.e. control and diabetic (25-60 years). In control group 120 (60 male: 60 female) and in diabetic group 120 subjects were taken. Subjects with history of smoking, renal diseases, coronary, arrhythmias, psychiatric disorders, thyroid disorders, arthritis and other chronic diseases like obstructive lung disease, tuberculosis etc. and participants with type 1 diabetes were excluded. Subjects having type 2 diabetes was included. Both male and female subjects with age ranging from 25-60 years. 
The informed consent of the subjects for the procedure and its consequences was taken prior to performing the test upon them.

\section{For Autonomic Function Test}

To assess the autonomic functions CANWin device was used. This device is PC Windows based Cardiac Autonomic Neuropathy (CAN) Analysis System with interpretation. It is used to analyse;

A. Sympathetic Parameters

- BP response to standing

- $\quad$ BP response to sustained handgrip

\section{B. Parasympathetic Parameters}

- Resting HR

- $\quad$ HR response to deep breathing (E/I ratio)

- HR response to standing (30:15)

- HR response to Valsalva manoeuvre

\section{METHOD}

Non-invasive autonomic function tests were performed by CANWin Analysis System. CAN Win$\mathrm{PC}$ is a window based Cardiac Autonomic Neuropathy (CAN) Analysis System with interpretation which has been unveiled by Genesis. "CANWin" detects Cardiac autonomic neuropathy based on Ewing battery of tests "CANWin" has a complete set of accessories that are required for the battery of tests.

\section{AUTONOMIC FUNCTION TESTS BY CANWin:} A. Tests of predominantly parasympathetic function:

1. Resting Heart Rate-. Normal resting heart rates ranges from 60-100 bpm.

2. Heart Rate variation during deep breathing (Expiration /Inspiration ratio): The ratio between longest $\mathrm{R}-\mathrm{R}$ interval during expiration and the shortest $\mathrm{R}-\mathrm{R}$ interval during inspiration (E/I ratio) in each respiratory cycle was calculated for evaluation.
3. Heart rate response to standing (30:15 ratio): The $30: 15$ is the ratio of the longest $\mathrm{R}-\mathrm{R}$ interval at beat 30 during inspiration/expiration cycle and the shortest R-R interval at beat 15 after standing.

4. Heart rate response to Valsalva maneuver (VM ratio): The Valsalva ratio $=$ Longest $\mathrm{R}-\mathrm{R}$ interval after maneuver (after the strain)/ shortest R-R interval during maneuver (during the strain) [5,6].

B. Test of predominantly sympathetic function:-

1. Blood - pressure response to standing: The $\mathrm{BP}$ of the subject was recorded at lying down position (supine) and again when the subject stands up from supine position.

2. Blood-pressure response to Sustained Handgrip (SHG): This test studies the blood pressure response to an isometric handgrip exercise.

\section{Analysis of Data}

Results obtained in control and diabetic subjects were compared in these groups and was analyses statistically.All data were expressed as mean \pm SD and were statistically analysed by using the Microsoft Excel and OpenEpi software (version 2.3.1). Student's t-test, One-way ANOVA and appropriate post-hoc tests (Bonferroni multiple comparisons procedure) was used to determine the statistical difference among parameters. p-values of less than 0.05 $(p<0.005)$ was indicated as statistically significant.

\section{RESULT}

Table-2 and Chart-1 are showing the comparison of Autonomic function test between the control and diabetic subjects. The results showed that in parasympathetic tests VM ratio and in sympathetic tests $\triangle \mathrm{SBP}, \triangle \mathrm{DBP}$ are highly significant, whereas $\mathrm{E}: \mathrm{I}$ ratio is significantly reduced in diabetic. The statistical analysis was done by Student's t- test.

Table-1: Normal, borderline and abnormal values of cardiovascular autonomic tests [7]

\begin{tabular}{|l|l|l|l|}
\hline Tests & Normal & Borderline & Abnormal \\
\hline Heart-rate (R-R interval) variation during deep breathing. (E:I ratio) & $\geq 1.21$ & $1.20-1.110$ & $\leq 1.10$ \\
\hline Heart-rate response to Valsalva maneuver (Valsalva ratio) & $\geq 1.21$ & - & $<1.21$ \\
\hline Immediate heart-rate response to standing (30:15 ratio) & $\geq 1.04$ & $1.01-1.03$ & $\leq 1.00$ \\
\hline $\begin{array}{l}\text { Blood-pressure response to sustained handgrip (increase in diastolic } \\
\text { blood pressure) }\end{array}$ & $\geq 16 \mathrm{mmHg}$ & $11-15 \mathrm{mmHg}$ & $<10 \mathrm{mmHg}$ \\
\hline Blood-pressure response to standing (fall in systolic blood pressure & $\leq 10 \mathrm{mmHg}$ & $11-29 \mathrm{mmHg}$ & $\geq 30 \mathrm{mmHg}$ \\
\hline
\end{tabular}

Table-2: Comparison of Autonomic Function Test Parameters

\begin{tabular}{|l|l|l|l|l|}
\hline \multirow{2}{*}{ Test Type } & $\begin{array}{l}\text { Cardiovascular } \\
\text { Reflex Test }\end{array}$ & CONTROL $(\mathbf{N = 1 2 0})$ & DIABETIC $(\mathbf{N}=120)$ & \multirow{2}{*}{ p-value } \\
\cline { 2 - 5 } & Mean \pm SD & Mean \pm SD & \\
\hline Parasympathetic Tests & E:I Ratio & $1.46 \pm 0.40$ & $1.25 \pm 0.32$ & $<0.05 \mathrm{~S}$ \\
\cline { 2 - 5 } & $30: 15$ Ratio & $1.28 \pm 0.40$ & $1.15 \pm 0.35$ & $>0.05 \mathrm{NS}$ \\
\cline { 2 - 5 } & VM Ratio & $1.73 \pm 0.62$ & $1.58 \pm 0.44$ & $<0.001 \mathrm{HS}$ \\
\hline \multirow{2}{*}{ Sympathetic Tests } & $\Delta$ SBP mm Hg & $3.43 \pm 1.56$ & $7.06 \pm 5.00$ & $<0.001 \mathrm{HS}$ \\
\cline { 2 - 5 } & $\Delta$ DBP mm Hg & $14.07 \pm 2.60$ & $5.6 \pm 3.54$ & $<0.001 \mathrm{HS}$ \\
\hline
\end{tabular}

Note: NS=Not Significant, $\mathrm{S}=$ Significant, HS=Highly Significant 


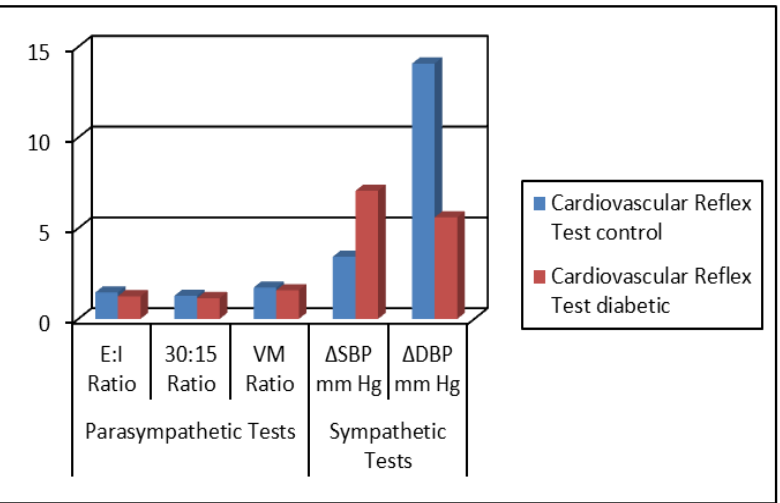

Chart-1

\section{DISSCUSSION}

In our study, patients with DM were found to have both sympathetic and parasympathetic dysfunctions. Autonomic function 30:15 ratio, E:I ratio, VM Ratio, $\triangle \mathrm{SBP}$ and $\triangle \mathrm{DBP}$ changes were observed in diabetic and control group . E:I ratio was reported lower in diabetic group. The decrease in the E/I ratio in the diabetic group may be due to the decreased vagal tone to the heart (bradycardia phase) during the expiration. Similar observations have been made by Khatoon $\mathrm{N}$ et al., 2010 [8], Krishna BH et al., 2014 [9], Jayabal M et al., 2015 [10] shown in Table-3. 30:15 ratio was significantly decreased in diabetic than the control group. This reflex phenomenon is due to unloading of the baroreceptors. Loss of this reflex may be due to loss of the sympathetic and parasympathetic response to standing. Similar trend was observed in Khatoon $\mathrm{N}$ et al., 2010 [8], Endukuru CK et al., 2013 [4], Bagherzadeh A et al., 2016 [11], Sucharita et al., 2016 [12] shown in Table-3. Valsalva ratio was significantly reduced in diabetic group than control group. This reflects decreased parasympathetic function due to decreased vagal tone. It is more sensitive test for both sympathetic and parasympathetic activities. The results obtained were similar to the study performed by Endukuru CK et al., 2013 [4], Krishna BH et al., [9]. 2014, Jayabal M et al., 2015 [10], Bagherzadeh A et al., 2016 [11], Sucharita et al., 2016 [12]. Present study reported that the systolic blood pressure was increased and it was found statistically significant in diabetic subjects as compared to the controls. This indicates the failure of baroreceptor reflex mechanism due to chronic hyperglycaemia which affects the autonomic nerves. Similar study were done by Endukuru CK et al., 2013 [4], Sucharita et al., 2016 [12]. In control subjects during sustained hand grip, a sharp rise in diastolic blood pressure was observed in diabetic subjects, which occur due to heart rate dependent increase in cardiac output with unchanged peripheral vascular resistance. Endukuru CK et al., 2013 [4], Krishna BH et al., 2014 [9], Jayabal M et al., 2015 ${ }^{10}$, Sucharita et al., 2016 [12] were found same result which was shown in Table-3.

Table-3: Comparison of autonomic function test between Control and Diabetic group by different author

\begin{tabular}{|c|c|c|c|c|c|}
\hline \multirow[t]{2}{*}{ Author name } & E:I & 30:15 & VM Ratio & $\begin{array}{l}\Delta \mathrm{SBP} \quad \mathrm{mm} \\
\mathrm{Hg}\end{array}$ & $\begin{array}{l}\triangle \mathrm{DDBP} \\
\mathrm{mm} \mathrm{Hg}\end{array}$ \\
\hline & Mean \pm SD & Mean \pm SD & Mean \pm SD & Mean \pm SD & Mean \pm SD \\
\hline Present study & $\begin{array}{l}1.46 \pm 0.40 \\
1.25 \pm 0.32 \\
<0.05 \mathrm{~S} \\
\end{array}$ & $\begin{array}{l}1.28 \pm 0.40 \\
1.15 \pm 0.35 \\
>0.05 \mathrm{NS} \\
\end{array}$ & $\begin{array}{l}1.73 \pm 0.62 \\
1.58 \pm 0.44 \\
<0.001 \mathrm{HS} \\
\end{array}$ & $\begin{array}{l}3.43 \pm 1.56 \\
7.06 \pm 5.00 \\
<0.001 \mathrm{HS} \\
\end{array}$ & $\begin{array}{l}14.07 \pm 2.60 \\
5.6 \pm 3.54 \\
<0.001 \mathrm{HS} \\
\end{array}$ \\
\hline Khatoon $\mathrm{N}$ et al., 2010 [8] & $\begin{array}{l}\text { (C) } 1.28 \pm 0.12 \\
\text { (D) } 1.05 \pm 0.08 \\
(p=0.04) \\
\text { (D) } 1.03 \pm 0.06 \\
(p=0.01) \\
(D) 1.02 \pm 0.02 \\
(p=0.02)\end{array}$ & $\begin{array}{l}1.11 \pm 0.18 \\
0.990 \pm 0.03 \\
(p=0.008) \\
0.986 \pm 0.06 \\
(p<0.001) \\
0.978 \pm 0.08 \\
(p=0.003) \\
\end{array}$ & - & - & - \\
\hline Endukuru CK et al., 2013 [4] & - & $\begin{array}{l}\text { (C) } 1.36 \pm 0.19 \\
\text { (D) } 1.17 \pm 0.12 \\
<0.01\end{array}$ & $\begin{array}{l}1.62 \pm 0.26 \\
1.32 \pm 0.22 \\
<0.01\end{array}$ & $\begin{array}{l}-2.9 \pm 0.41 \\
-7.0 \pm 1.22 \\
<0.01\end{array}$ & $\begin{array}{l}15.9 \pm 0.83 \\
11.5 \pm 0.96 \\
<0.01\end{array}$ \\
\hline Krishna BH et al., 2014 [9] & $\begin{array}{l}\text { (C) } 13.48 \pm 3.57 \\
\text { (D) } 6.10 \pm 3.37 \\
<0.001\end{array}$ & - & $\begin{array}{l}1.18 \pm 6.28 \\
0.87 \pm 0.21 \\
<0.001\end{array}$ & - & $\begin{array}{l}13.24 \pm 2.56 \\
6.28 \pm 2.85 \\
<0.001 \\
\end{array}$ \\
\hline Jayabal M et al., 2015 [10] & $\begin{array}{l}\text { (C) } 1.255 \pm 0.11 \\
\text { (D) } 1.099 \pm 0.05 \\
<0.001\end{array}$ & - & $\begin{array}{l}1.40 \pm 0.05 \\
1.20 \pm 0.12 \\
<0.001\end{array}$ & - & $\begin{array}{l}10.13 \pm 1.89 \\
3.20 \pm 1.54 \\
<0.001\end{array}$ \\
\hline $\begin{array}{l}\text { Bagherzadeh A et al., } 2016 \\
\text { [11] }\end{array}$ & - & $\begin{array}{l}\text { (C) } 1.27 \pm 0.13 \\
\text { (D) } 1.23 \pm 0.20 \\
0.29\end{array}$ & $\begin{array}{l}1.58 \pm 0.28 \\
1.44 \pm 0.31 \\
0.01\end{array}$ & - & - \\
\hline Sucharita et al., 2016 [12] & - & $\begin{array}{l}\text { (C) } 1.36 \pm 0.19 \\
\text { (D) } 1.17 \pm 0.12 \\
<0.01\end{array}$ & $\begin{array}{l}1.62 \pm 0.26 \\
1.32 \pm 0.22 \\
<0.01\end{array}$ & $\begin{array}{l}4.07 \pm 11.1 \\
-9.7 \pm 14.9 \\
<0.01\end{array}$ & $\begin{array}{l}8.9 \pm 11.1 \\
1.9 \pm 8.4\end{array}$ \\
\hline
\end{tabular}




\section{CONCLUSION}

Our study concluded that values of parasympathetic tests were observed to be lower and sympathetic tests were higher in diabetic, when compare with control and statistically highly significant $(\mathrm{p}<0.001)$. In our study, patients with DM were found to have both sympathetic and parasympathetic dysfunctions due to hyperglycaemic effect. In the diabetic group the decreased vagal tone to the heart and nerve impairment is first seen in the long fibres. Hence, parasympathetic nerve impairment is the first and foremost manifestations of autonomic neuropathy in DM. Sympathetic nerve impairment follow later. This indicates that parasympathetic impairment was more than the sympathetic impairment in diabetic.

\section{REFERENCES}

1. Aggarwal S, Tonpay PS, Trikha S, Bansal A. Prevalence of autonomic neuropathy in Diabetes Mellitus. Curr Neurobiol. 2011;2(2):101-5.

2. Schummer MP, Joyner SA, Pfeifer MA. Cardiovascular autonomic neuropathy testing in patients with diabetes. Diabetes Spectr. 1998; 11:227-231.

3. American Diabetes Association and the American Academy of Neurology, Consensus statement: Standardized measure in diabetes neuropathy. Diabetes Care, 1995;18:59-82.

4. Endukuru CK, Mallikarjuna Reddy N. A comparative study of autonomic function sensitivity testing in type 2 diabetes. Int J Sci Res. 2015 Apr;4:1796-9.

5. Stewart JM, Medow MA, Bassett B, Montgomery LD. Effects of thoracic blood volume on Valsalva maneuver. American Journal of Physiology-Heart and Circulatory Physiology. 2004 Aug;287(2):H798-804.

6. Maser RM. Autonomic neuropathy: patient care. Diabetes spectrum. 1998;11(4):224-227.

7. Ewing DJ, Clarke BF. Diagnosis and management of diabetic autonomic neuropathy. British medical journal (Clinical research ed.). 1982 Oct 2;285(6346):916-918.

8. Khatoon N, Kumar BS, Hazari MA Cardiovascular autonomic neuropathy in patients with diabetes mellitus. International Journal of Pharma and Bio Sciences. 2010 Sep 30.

9. Krishna BH, Mallikarjuna Reddy N, Sharan B, Singh M, Sasi Kala P, Kiran Kumar CH, Uma BV, Vijetha P. Cardiovascular autonomic neuropathy in diabetics: Correlation with duration of diabetes. Biomedical Research. 2014; 25(3):307-310.

10. Jayabal M, Thangavel D, Thiyagarajan UM, Ramasamy N, Rangan V, Subramaniyam V. Classical autonomic function tests in patients with Type 2 diabetes mellitus and healthy volunteers: A comparative study. National Journal of Physiology, Pharmacy and Pharmacology. 2015;5(1):68-71.

11. Bagherzadeh A, Nejati-Afkham A, TajallizadeKhoob Y, Shafiee A, Sharifi F, Esfahani MA, Badamchizade $\mathrm{Z}$, Alatab $\mathrm{S}$, Fakhrzadeh $\mathrm{H}$. Association of cardiac autonomic neuropathy with arterial stiffness in type 2 diabetes mellitus patients. Journal of Diabetes \& Metabolic Disorders. 2013 Dec;12(1):55.

12. Sucharita S, Bantwal G, Idiculla J, Ayyar V, Vaz M. Autonomic nervous system function in type 2 diabetes using conventional clinical autonomic tests, heart rate and blood pressure variability measures. Indian journal of endocrinology and metabolism. 2011 Jul;15(3):198. 